\title{
Manifiesto nacionalista (o hasta separatista, si me apuran)
}

\author{
C. Ulises MOULines
}

Seminar für Philosophie, Logik und Wissenschaftstheorie

Ludwig Maximilians-Universität München

moulines@lrz.uni-muenchen.de

\begin{abstract}
RESUMEN: La doble tesis de este ensayo es que el nacionalismo, como programa de defensa y desarrollo de las naciones, es una doctrina bien fundada tanto en el nivel ontológicoepistemológico como en el axiológico. La parte ontológico-epistemológica de la tesis es que las naciones son entidades empíricas reales, si bien no identificables de manera directa, sino por vía teórica, al igual que tantas otras entidades teóricas de las ciencias más avanzadas. Las naciones son tipos especiales de etnias; se esboza aquí una "miniteoría" que fija los "axiomas mínimos" que determinan dichas entidades. La tesis axiológica es que es algo bueno que el universo (en especial el dominio sociocultural) consista en la mayor diversidad posible de cosas; en consecuencia, un programa ético-político como el nacionalismo, que aboga por la preservación y el desarrollo de las naciones, debe ser valorado positivamente.
\end{abstract}

PALABRAS CLAVE: conceptos teóricos, etnia, nación, nacionalismo.

\section{TRES TESIS}

Un fantasma recorre las cancillerías de Europa. Y no sólo las cancillerías, sino también los parlamentos, la prensa, las universidades y la así llamada "opinión pública" en general. Y no sólo de Europa, sino del mundo entero. No se trata del espectro del que hablaban Marx y Engels en su Manifiesto de hace siglo y medio. El fantasma que ahora atemoriza a gobiernos, parlamentos, periodistas e intelectuales muestra rasgos muy diferentes del anunciado por los comunistas: es el fantasma del nacionalismo. Parece que cualquier persona decente ha de atribuirle la responsabilidad por las calamidades que tanto hacen sufrir a la humanidad actualmente.

Este espectro es el objeto de consideración del presente ensayo. Me propongo defender tres tesis al respecto. La primera es de carácter empírico (y como tal, en principio indigna de un filósofo, pero a veces el carácter acuciante de los problemas nos obliga a los filósofos a transgredir los límites disciplinarios): el nacionalismo es un fenómeno cultural profundo, no una moda pasajera. La segunda es de carácter metodológico, y es la tesis central que me interesa defender: puede constatarse un notable déficit conceptual y metodológico en el tratamiento usual del fenómeno del nacionalismo por parte de las disciplinas socioculturales pertinentes. Este déficit es una 
manifestación más de una determinada forma de indigencia metodológica muy divulgada aun en las ciencias de la cultura. La tercera y última tesis es de carácter ético-político (y, como tal, indigna de un filósofo de la ciencia - pero, por las mismas razones de la primera tesis, me creo justificado en transgredir fronteras): ella se desprende en realidad como corolario práctico, y a mi parecer evidente, de las dos tesis anteriores; puede resumirse en el lema: iViva el nacionalismo!

Empecemos por una hipótesis sociopsicológica, que me parece bien apoyada en los datos y que permite entender un gran número de fenómenos políticos, sociales y culturales, tanto del presente como de épocas pasadas: la raíz psicológica del nacionalismo es una emoción fuerte y duradera en muchos seres humanos, una emoción que, desde tiempos antiguos, se conoce como "amor a la patria", si bien esta expresión ha caído en desuso en los medios intelectuales. Al igual que cualquier otra emoción fuerte y básica, si se la canaliza sensatamente, puede resultar muy creativa; pero si se la deforma o reprime, puede manifestarse de modo muy destructivo. Constatamos los mismos efectos ante otros tipos de amores que en general se valoran positivamente: el amor propio (en el sentido de amor a la propia dignidad), el amor a la pareja, el amor a los hijos, o incluso el amor a cosas más abstractas como pueden ser la libertad o el conocimiento.

Ciertamente, algunos filósofos que se autoconsideran "racionalistas" calificarán dichas emociones de "irracionales". Pero incluso un filósofo "racionalista", como persona de carne y hueso, reaccionará enojado si lo humillan, se entristecerá si su pareja lo abandona o se le muere un hijo, tratará de evitar que lo metan en la cárcel y le asustará la perspectiva de acabar padeciendo el mal de Alzheimer. El filósofo racionalista también está sujeto a los amores irracionales antedichos. Por lo demás, una subtesis que postulo aquí de pasada, sin disponer del espacio para justificarla, es que los calificativos "racional" o "irracional" no sirven de nada cuando se trata de entender los asuntos humanos.

En cualquier caso, lo común a estas emociones amorosas, sean "racionales" o "irracionales", es que son naturales e inevitables en la inmensa mayoría de los seres humanos y que se caracterizan por un fuerte sentimiento de filiación hacia un objeto que el individuo siente que lo trasciende, algo que percibe a la vez como objeto externo a sí mismo y componente fundamental de su propia identidad. Este "algo" externo e íntimo a la vez puede estar constituido por entidades muy concretas como la pareja o la familia, entidades muy abstractas como el conocimiento científico, o bien, en fin, cosas que ni son tan concretas ni tan abstractas, como la propia dignidad, la libertad. . . o justamente la patria. Para dar satisfacción a tales emociones de 
amor, el individuo es capaz de desplegar dosis extraordinarias de energía, enfrentar grandes peligros o incluso sacrificar la propia vida.

Naturalmente, del hecho de que se den una serie de emociones de fuerte filiación o auto-trascendencia, muchas de las cuales son generalmente aceptadas como connaturales al ser humano o incluso altamente valiosas, no se desprende que la emoción nacional, el amor a la patria, sea justamente una de ellas. El antinacionalista puede aducir que, si bien podemos aceptar o incluso evaluar positivamente impulsos tales como el amor a la propia dignidad, a la pareja, a la familia o al conocimiento, en cambio hay que repudiar el amor a la patria. Es en este punto que arranca nuestra discusión. El antinacionalista es el adversario de una determinada emoción, la realidad psicológica de la cual no puede negar, pero a la cual considera como un grave desorden psíquico, que debe ser reprimido o superado a cualquier precio. ¿Qué razones pueden aducirse para declararse adversario de la emoción nacional?

\section{DOS ANTÍTESIS: EL NEGACIONISMO Y EL CONTRANACIONALISMO}

Creo que hay dos líneas de ataque básicas y prima facie plausibles que el crítico del nacionalismo puede plantear seriamente y de hecho se han planteado en la literatura sobre el tema. Es frecuente que ambas líneas de argumentación antinacionalista se mezclen, pero conceptual y metodológicamente hay que mantenerlas separadas: las premisas respectivas son muy diferentes, a pesar de que conducen en definitiva a la misma conclusión. El primer tipo de argumento parte de lo que podemos denominar "la tesis negacionista" y el segundo de lo que llamaré "la posición contranacionalista". ${ }^{1}$

La tesis negacionista postula que no existe ninguna entidad real que pueda considerarse el referente del término "nación tal-o-cual", a menos que entendamos por este concepto simplemente un Estado soberano. El concepto específico de nación, en tanto que diferente del de Estado, sería así un concepto vacío. El nombre propio de una nación, si no lo utilizamos para designar un Estado (o quizás un territorio geográfico) se referiría a una entidad mítica o ficticia. Así, "Croacia" hasta el año 1992 o "Kurdistán" en la actualidad, en la medida en que no se utilicen sólo para designar una región geográfica como pueda ser la Patagonia o los Alpes, serían términos que designarían lo mismo que "Zeus" o "Pegaso"; o sea, nada.

1 Supongo que es innecesario advertir aquí que lo que denomino "negacionismo" en este contexto no tiene nada que ver con el uso de este término frecuente en los detractores de la posición revisionista en la historiografía contemporánea, en especial con respecto a la historia de la Segunda Guerra Mundial. 
Los orígenes del negacionismo en el pensamiento político-jurídico del siglo xx pueden retrotraerse seguramente al positivismo jurídico de Hans Kelsen. Según su influyente Teoría del Derecho, la única entidad de la que tiene sentido ocuparse en este contexto, es del Estado como unidad jurídicoadministrativa, bien definida por una Constitución y un sistema de normas. En su obra fundamental, la Teoría pura del derecho, Kelsen sostiene explícitamente que la idea de que el Estado pueda "representar" algo distinto de sí mismo - la voluntad de la nación por ejemplo- responde a una ficción científicamente insostenible. $^{2}$

Inspirado en la doctrina kelseniana, el negacionismo está muy difundido en la terminología (y por tanto también en la aprehensión de los problemas) característica del ámbito político actual. Por ejemplo, la disciplina llamada "Derecho Internacional" sigue fielmente las huellas de Kelsen y en la práctica no es otra cosa que "Derecho Interestatal". Ya el propio Kelsen había sentenciado lapidariamente que el único sentido del Derecho Internacional (Völkerrecht) estriba en regular la conducta entre los Estados. ${ }^{3}$ Por consiguiente, sólo tiene sentido ocuparse de las relaciones jurídicas entre los Estados como unidades administrativas, no de las relaciones jurídicas entre las naciones, si las suponemos entidades diferentes de los Estados.

De raíz kelseniana es también la denominación de la máxima instancia política en el nivel planetario, encargada, en principio, de resolver los problemas político-jurídicos del planeta: se autodenomina "Organización de las Naciones Unidas", cuando en realidad debería llamarse, para evitar confusiones y falsas expectativas, "Organización de los Estados Unidos".

(Primer excurso: por razones obvias, la organización en cuestión no puede calificarse en la actualidad de los "Estados Unidos" porque dicha denominación suele utilizarse para designar el único país de la Tierra que hasta ahora ha desdeñado darse un nombre propio. De hecho, "Estados Unidos" no es una denominación unívoca, pues hay muchos Estados de estructura federal en el mundo; tampoco "Estados Unidos de América" es un nombre propio, pues "América" es el nombre de un continente en el que existe una treintena de Estados soberanos; además, aparte de los mal llamados "Estados Unidos de América", en el continente americano existen por lo menos otros dos Estados con la denominación "Estados Unidos", a saber: los "Estados Unidos Mexicanos" y los "Estados Unidos del Brasil". Así, pues, ni "Estados Unidos" ni "Estados Unidos de América", ni obviamente "América", son designaciones correctas para un solo país. Como los habitantes de dicho país han desdeñado hasta ahora darse a sí mismo y a su Estado un nombre propio, está justificado que seamos los demás quienes los

2 Cfr. H. Kelsen, Reine Rechtslehre, Franz Deuticke, Viena, 1960, p. 302.

3 Ibid., p. 337. 
bauticemos con una verdadera designación unívocamente referencial. Propongo una denominación ya bastante difundida en los países latinoamericanos: "gringos" para los habitantes de dicho país y "Gringolandia" para su Estado. Ambas denominaciones son perfectamente unívocas e inconfundibles. Fin del excurso.)

La confusión entre Estado y nación es aún más sorprendente por parte de muchos politólogos, de quienes podría esperarse un poco más de exactitud conceptual que de los no especialistas. Por ejemplo, en la edición más reciente que conozco (de 1996) del influyente Oxford Concise Dictionary of Politics, no encontramos ninguna entrada para el término "nación", y sí en cambio una para el término "Estado-nación" ("nation-state"). Al parecer, para los editores de esta obra de consulta politológica es indiscutible que el marco estatal es el único dentro del cual tiene sentido utilizar el término "nación". En el transcurso del largo artículo sobre "Estado-nación", firmado por Paul Ingram, encontramos una breve descripción de lo que, según el autor, caracteriza el concepto de nación: "un constructo mítico [...] con una fuerza política altamente persuasiva y poderosa". Y más adelante añade: “Cuando los dos conceptos, 'nación' y 'Estado' se combinan, eso crea una mezcla enormemente compulsiva de legitimidad y eficiencia para las élites gobernantes."

He aquí lo que podríamos llamar "la concepción clásica del negacionismo": en principio, en las ciencias políticas no tiene sentido hablar de naciones (aparte de los Estados) porque tales cosas no existen; ahora bien, es innegable que muchas veces la gente se embarca en aventuras muy arriesgadas en nombre de una nación y no de un Estado. Por lo tanto, se trata de un mito con una fuerza terrible. ¿Y de dónde le viene esta fuerza al mito? Sin duda no de un fundamento en la realidad, sino de la manipulación a la que están sometidas las masas crédulas por parte de élites gobernantes que quieren legitimar su poder.

Ahora bien, nótese que el texto de Ingram fue publicado en 1996. Es decir, siete años después de la caída del muro de Berlín, cinco años después de la disolución de la Unión Soviética y cuatro años después de que comenzara en los Balcanes una lucha muy cruenta que desembocó en la fragmentación de la antigua Yugoslavia. Al primero de estos acontecimientos se le suele describir, y parece plausible hacerlo así, diciendo que, con la caída del muro de Berlín, se abrió la puerta a la reunificación de los dos Estados alemanes de una única nación alemana. El hilo conductor de este proceso fue el lema que clamaban las masas de Alemania Oriental en las impresionantes manifestaciones del otoño de 1989: "Wir sind ein Volk" "Somos una sola nación"). Este lema, por cierto, no fue inventado por las "élites gobernantes" del Estado de Alemania Oriental, a las cuales la frase en cuestión 
no les hacía ninguna gracia. En cuanto al segundo acontecimiento político mencionado, es normal describirlo diciendo que el unitario Estado soviético (en singular) fue fragmentado, a pesar de la resistencia de la nomenklatura (o sea, de la élite gobernante), por el impulso a la independencia de una docena de naciones que carecían de Estado propio. Finalmente, parece verosímil describir el tercer caso, el de la antigua Yugoslavia, como el de la lucha de diversas naciones que querían crear sus propios Estados soberanos en contra de la voluntad hegemónica de la élite en el gobierno perteneciente a otra nación: la servia. Estas tres descripciones dadas son empíricamente bastante verosímiles y, en todo caso, cualquier persona desprejuiciada las entiende; pero resultarían ininteligibles si tuviera razón un negacionista como el autor del citado artículo. Se trataría de descripciones sin sentido o, en el mejor de los casos, de algo así como un cuento de hadas. El precio metodológico que el negacionista se ve obligado a pagar por tratar de compatibilizar estos tres ejemplos históricos recientes con su esquema teórico general me parece desmesuradamente elevado.

No obstante, volvamos a examinar las consecuencias generales del negacionismo. De él se desprende que la emoción nacional, el amor a la patria, es el producto de una ilusión, o quizás incluso de una alucinación; sería un caso de demencia colectiva. Sería comparable, por ejemplo, con la fuerte emoción que los conquistadores españoles sentían por El Dorado, una atracción irresistible y arriesgada por algo que no existe y que ha sido inventado por mentes calenturientas. La consecuencia práctica moral de esta situación sería que deberíamos esforzarnos por curar a quienes padecen tan grotesca alucinación nacionalista por todos los medios disponibles: pedagógicos, psicoterapéuticos, o si es necesario, por la coerción administrativa (censura, multas, etc.) o incluso física (la cárcel)...

La posición negacionista tiene pues un contenido fáctico y a la vez normativo: favorece una determinada actitud normativa basada en la descripción de un supuesto hecho negativo, a saber, la inexistencia real de las naciones. En cambio, la otra posición contraria al nacionalismo que hemos de examinar, la que he llamado "contranacionalismo", se manifiesta de manera puramente evaluativa o normativa. El contranacionalismo no niega la existencia real de las naciones (como algo distinto de los Estados), ni siquiera su importancia para comprender muchos sucesos históricos; pero las considera realidades nefastas, entidades que, por desgracia, son bien reales, tan reales como un microorganismo infeccioso. Como tales, las naciones deberían ser erradicadas, o al menos tendrían que ser reducidas a una mínima expresión. $\mathrm{El}$ argumento es, a grandes rasgos, el siguiente: las naciones son la causa, o al menos una condición necesaria, para el surgimiento del nacionalismo; éste, a su vez, es la causa mediata o inmediata de un gran número de desastres 
para la humanidad (guerras, crisis económicas, manipulación de las masas por parte de élites corruptas, etc.). Por consiguiente, si aplicamos un modus tollens práctico, podemos inferir que hay que eliminar las naciones o bien, si eso no es del todo posible, reducirlas a una expresión meramente folclórica, para hacerlas inofensivas. El contranacionalismo es pues un programa de acción política basado en una evaluación decididamente negativa de las entidades que llamos "naciones".

Como mi propósito explícito es defender el nacionalismo, voy a emprender a continuación la crítica de las dos posiciones antinacionalistas descritas. Sin embargo, está claro que antes hay que examinar con la mayor precisión posible el concepto de nación, el cual es naturalmente central en esta discusión.

\section{III. ¿QQUÉ ES UNA NACIÓN?}

Una primera ojeada a la literatura relevante nos hace ver pronto la gran indigencia teórica con la cual se usa el concepto de nación. Ello lo constatamos incluso en obras de referencia que pretenden establecer cánones de precisión metodológica y gozan de un amplio reconocimiento. Ya hemos visto que el Oxford Dictionary of Politics no contiene ninguna entrada específica para el término "nación" y que este término se usa generalmente ya sea como sinónimo de Estado ya sea como si denotara una entidad mítica. Ninguna de las dos acepciones permite explicar satisfactoriamente un gran número de acontecimientos sociales, culturales y políticos, de los que he dado tres ejemplos recientes; podríamos multiplicar los ejemplos hasta la saciedad.

La Enciclopedia Internacional de las Ciencias Sociales se toma la problemática de las naciones de manera un poco más seria que el Diccionario de Oxford, veinte años posterior. En efecto, en ella encontramos una larga entrada sobre el término "nación", que empieza con una declaración esperanzadora: "La nación ha llegado a ser considerada como el concepto político fundamental de los tiempos recientes." (Utilizo la versión en castellano de dicha Enciclopedia, dirigida por Vicente Cervera Tomás.) He aquí una evaluación bastante diferente de la de los politólogos de Oxford. No obstante, si seguimos leyendo, quedaremos algo decepcionados porque el autor del artículo, Dankwart A. Rustow, reconoce una gran ambigüedad en el uso del término "nación", ambigüedad que él mismo no se atreve a resolver: " 'Nación' es, o bien sinónimo de un Estado [...], o bien denota un grupo humano ligado por la solidaridad común, un grupo cuyos miembros colocan la lealtad al grupo como totalidad por encima de cualesquiera otras lealtades contrapuestas." Rustow nos advierte que la segunda inter- 
pretación tiene una larga tradición, ya que proviene de John Stuart Mill (si bien éste hablaba de "nacionalidad" en vez de "nación", pero esta diferencia terminológica no es importante aquí). La definición que encontramos en las Consideraciones sobre el gobierno representativo de Mill, publicadas por primera vez en 1861, es, en efecto, la siguiente: "Puede decirse que una parte de la Humanidad constituye una nacionalidad [...] si sus miembros están unidos entre sí por simpatías comunes, que no existen entre ellos y otras personas, lo cual los hace cooperar entre sí de mejor gana que con cualquier otro pueblo, a desear estar sometidos al mismo gobierno y a desear que haya un gobierno integrado exclusivamente por ellos o por una parte de ellos." 4

Siempre es bueno regresar a los clásicos. La definición de Mill es más fructífera que las posteriores reducciones negacionistas o paranegacionistas. En cualquier caso, nos permite distinguir claramente entre nación y Estado. Lo que caracteriza una nación, según Mill, no es que ella ya sea un Estado, sino que es algo que quiere tener un Estado, y ello es así porque la esencia de la nación radica en el vínculo de solidaridad y cooperación, el cual es más fuerte entre sus miembros que con los miembros de otras naciones.

La definición de Mill es muy digna de consideración pero tampoco es del todo satisfactoria. En primer lugar, también es reduccionista y, en particular, psicologista (lo cual no debe extrañarnos de parte de Mill): reduce la identidad propia de la nación a los sentimientos de simpatía mutua entre sus miembros. Pero aparte de este fallo de índole metodológica, está la escasa verosimilitud empírica de la reducción psicológica en términos de simpatía. Mucha gente puede sentir profunda antipatía o desprecio hacia sus connacionales y, no obstante, seguirá perteneciendo a la misma nación que ellos. Un caso típico en este sentido es el de los alemanes, quienes incluso han acuñado un término específico para referirse a un sentimiento muy divulgado entre ellos: "Selbsthaß", o sea, "autoodio". Recordemos cómo, incluso desde antes de la Segunda Guerra Mundial, un número considerable de alemanes ha sentido, a priori, más simpatía por un extranjero, sobre todo si éste es europeo occidental o anglosajón, que por la mayoría de sus connacionales. Lo cual no les impide ser alemanes, incluso "muy alemanes", podríamos decir. Otro caso parecido, de origen muy diferente pero de efectos comparables, es el del insalvable desprecio que sienten con frecuencia los estratos "superiores" de las sociedades latinoamericanas por la inmensa mayoría de la población de sus respectivos países; este sentimiento de desprecio no les redime de ser latinoamericanos, incluso "muy latinoamericanos" (aunque prefirieran ser anglosajones, franceses...

4 Cfr. J. St. Mill, Considerations on Representative Government, Liberal Arts, Nueva York, 1958, cap. 16. 
o incluso españoles —véase el caso de un renombrado novelista peruano). Basten, pues, estos contraejemplos para descartar la definición de nación como "clase de equivalencia de máximas simpatías mutuas".

Un autor reciente, que ha hecho un verdadero esfuerzo por acotar el concepto de nación, distinguiéndolo claramente del de Estado, es Luis Villoro. En su reciente obra sobre el tema,${ }^{5}$ sin pretender dar una definición formal, postula cuatro condiciones necesarias que ha de cumplir un grupo humano para que se le pueda aplicar el rótulo de "nación": 1) comunidad de cultura; 2) conciencia de pertenencia; 3) proyecto común; 4) relación con un territorio. En muchos aspectos, me reconozco plenamente en las ideas desplegadas por Villoro en esta obra, que representa el tratado más sistemático y ponderado que conozco sobre el tema. Además, es uno de los pocos autores relevantes en este contexto que no culmina su análisis en un alegato puro y duro contra el nacionalismo (aunque probablemente Villoro no aceptaría ser etiquetado como "nacionalista", etiqueta con la que yo, por mi parte, no tengo ningún problema). No obstante, creo tener que diferir en cuanto a los fundamentos conceptuales de su enfoque, por razones que espero quedarán claras más abajo. De momento baste notar que las cuatro condiciones "necesarias" de pertenencia a una nación que él propone son bastante problemáticas: o bien se las entiende de una manera tan vaga y amplia que prácticamente cualquier par de personas tomadas al azar acabarían perteneciendo a la misma nación, o bien, si se las restringe un poco, es fácil encontrar numerosos contraejemplos, con lo cual su carácter de "condiciones necesarias" resulta espurio. Pasemos lista brevemente a estos problemas. La noción de "comunidad cultural" puede estirarse tanto que el profesor de filosofía Villoro, pongamos por caso, y un agente bursátil japonés acaben por pertenecer a la misma comunidad cultural (la de la "modernidad", por ejemplo); o bien, si se dan criterios más estrictos, muy pronto el mismo profesor de filosofía Villoro dejará de pertenecer a la misma comunidad cultural que su compatriota de la esquina, vendedor de tacos. Mutatis mutandis vale para lo del "proyecto común". En cuanto a la "conciencia de pertenencia", los ejemplos ya citados de los alemanes, o de las élites latinoamericanas, nos conminan a andarnos con mucho cuidado con esa idea; además, muchas personas no son conscientes de que pertenecen a una nación sino en circunstancias especiales (por ejemplo, debido a que han tenido que emigrar o a que se ven enfrentados a una inmigración masiva de personas de otra nación). Al igual que el burgués gentilhombre de Molière, que no sabía que hablaba en prosa hasta que se lo dijeron, mucha gente sólo se entera de que pertenece a la nación tal o cual hasta que alguien los

${ }^{5}$ Cfr. L. Villoro, Estado plural, pluralidad de culturas, Paidós/unam, México, 1998, pp. 13 y ss. 
hace conscientes de ello; pero eso no implica que antes no pertenecieran ya a esa nación. Finalmente, la "relación privilegiada con un territorio" es sin duda una condición frecuente de nacionalidad pero en absoluto necesaria (baste recordar el caso de la nación judía durante casi dos milenios o el de la nación gitana desde hace un milenio).

En cualquier caso, el primer mérito fundamental del ensayo de Villoro, implícito ya en el enfoque de Mill, es establecer claramente que el concepto de nación no tiene nada que ver con el de Estado. El término "Estado" denota una entidad jurídico-administrativa, casi siempre definida por una Constitución y unas Leyes Fundamentales, y siempre asociada a un territorio con fronteras físicas bien definidas (aunque puedan cambiar con el tiempo). En cambio, el término "nación" no pertenece al orden jurídico sino al político o etnológico. Las naciones no están bien delimitadas por fronteras geográficas; como acabo de indicar mediante dos contraejemplos, ni siquiera es necesario para su existencia estar vinculadas a un territorio determinado. Mucho menos pueden identificarse las naciones con una Constitución política, que puede cambiar cada docena de años, sin que por ello deje de existir la nación como tal. En resumen: aún no sabemos bien a bien lo que es una nación, pero seguro que no es una entidad idéntica a un Estado.

Ahora bien, como ya advertía Mill, aunque las naciones no son idénticas a los Estados, es característico de ellas que deseen disponer de un Estado propio, en tanto instrumento jurídico-político para defender su identidad nacional y desarrollarla. Y, justamente cuando no lo logran, generalmente debido a coacciones externas, suele manifestarse, al menos en una porción considerable de sus miembros, la intensa emoción que conduce al nacionalismo combativo. Cualquier forma de amor, y en particular el amor a la patria, cuando es constantemente frustrado, puede volvernos "locos de amor". Cuando a un individuo se le cortan las posibilidades de desarrollo de un modo que considera injusto o arbitrario, no hay por qué extrañarse si se enoja y reacciona con violencia. Lo mismo pasa con las naciones, cuyo desarrollo es percibido por muchos de sus miembros también como condición de posibilidad de su propio desarrollo individual o el de familiares y amigos. He aquí el origen evidente de un gran número de conflictos políticos y militares en el mundo. Esta constatación, naturalmente, es una trivialidad. Pero una trivialidad que el negacionista, al negar la realidad de las naciones, no puede comprender. Según un informe del Departamento de Estudios sobre la Paz de la Universidad de Uppsala, de los 111 conflictos armados en curso durante el año 1988 (o sea, antes de que se empezara a hablar tanto del llamado "resurgimiento de los nacionalismos"), sólo 12 consistían en enfrentamientos entre los ejércitos regulares de Estados soberanos diferentes; el resto de los combates, o sea 90\% (!), provenían de conflictos violentos 
dentro de un mismo Estado. ${ }^{6}$ La inmensa mayoría de estos conflictos eran intra-estatales pero inter-nacionales en el sentido genuino de la palabra, es decir, enfrentamientos entre dos o más naciones dentro de un mismo Estado. Eso era hace más de diez años. No dispongo de una estadística más reciente, pero no hay duda de que, desde entonces, el número y la virulencia de este tipo de luchas ha aumentado drásticamente. Basta tener presente todo lo que en la última década del milenio ha pasado y sigue pasando en el seno de la ex Unión Soviética, de la antigua Yugoslavia, del África subsahariana, de prácticamente todo el Asia excepto Japón, de algunos países de América Latina (México, Perú) e incluso de Europa Occidental. Puede tacharse a estos sucesos de "irracionales", pero con ello no explicaremos nada. No podemos prescindir del concepto de nación si queremos entender algo de lo que pasa en el mundo.

Ahora bien, sería un error (o una infamia) concluir que es sólo para dar cuenta de situaciones de violencia que es pertinente el concepto de nación. Hay muchos otros procesos socioculturales que resultan más inteligibles si admitimos que son la manifestación de la constitución de una nación o de la diferenciación entre naciones. Con frecuencia, estos procesos son previos al proyecto político de constitución de un Estado nacional. Por ejemplo, en la rápida difusión del protestantismo en la región geográfica llamada ahora "Alemania", desempeñó sin duda un gran papel la autopercepción más o menos consciente, por parte de amplios sectores de la población, de una identidad nacional claramente diferenciada del Sur latino. Más evidente aún es que el Risorgimento italiano de fines del siglo xviI, como movimiento literario, fue precursor de la constitución de un Estado unitario en Italia. Finalmente, el notable florecimiento de la música culta checa, eslovaca y húngara en el seno del Imperio Austro-Húngaro puede considerarse premonitorio de la independencia estatal de estas naciones medio siglo después.

Mi argumento en pro del uso del concepto de nación es un caso de lo que en la terminología metodológica técnica se llama un argumento abductivo: si admitimos la existencia de naciones, podremos explicar una serie de fenómenos políticos y culturales importantes que de otro modo quedarían muy mal explicados. Claro que el negacionista será reacio a aceptar este argumento abductivo. Lo único que vemos, nos dirá, es que, en determinadas regiones del planeta, determinados grupos de personas toman las armas y empiezan a matarse entre sí, o bien cambian unos ritos religiosos por otros, o desarrollan nuevas formas melódicas, etc. Pero yo no veo en todo eso ninguna nación, nos objetará. He aquí el problema básico del negacionista: para decirlo de una vez, el negacionista representa, en la explicación de los fenómenos político-culturales, una metodología clásicamente positivista o

${ }^{6}$ Cfr. World Directory of Minorities, 1990, p. XIII. 
empirista radical. Para él, los únicos conceptos sociales o políticos que tienen sentido son aquellos que se refieren a entidades accesibles directamente a los órganos de los sentidos, conceptos que se refieren a cosas como seres humanos y la conducta que manifiestan, las lenguas que hablan, la música que tocan, los monumentos que construyen y quizás incluso los códigos jurídicos que redactan, porque éstos al menos se ven escritos negro sobre blanco. Pero, ¿quién ha visto, oído o tocado jamás una nación?

Pues bien, si algo hemos aprendido del desarrollo de la filosofía de la ciencia del siglo xx es que la epistemología positivista o empirista radical es definitivamente insostenible, y que la metodología que la acompaña, el operacionalismo, tomada al pie de la letra, conduce a desastres metodológicos. El operacionalismo fue inventado por dos físicos, Ernst Mach y P.W. Bridgman, quienes temían que la metafísica se colara dentro de la física. Para ellos, cualquier término científico debía venir definido por configuraciones directamente observables y controlables de cuerpos macroscópicos. Afortunadamente, los propios físicos no les hicieron caso, y siguieron introduciendo y utilizando conceptos no definibles en términos observacionales, desde "electrón" hasta "quark", pasando por "curvatura del espacio-tiempo" y "flujo de entropía". De hecho, los físicos clásicos ya habían tomado una actitud bastante despreocupada respecto al supuesto carácter observacional de las entidades sobre las que hablaban (aunque en sus "sermones" divulgatorios hicieran gala de un empirismo a ultranza): conceptos tales como "fuerza de gravedad", "energía" o "campo de gravitación" no cumplen, ni con la mejor buena voluntad, los criterios operacionalistas. Todos estos conceptos son ejemplos de lo que, en la terminología particular de la filosofía de la ciencia, se denomina "conceptos teóricos".

Lo característico de los conceptos teóricos (en el sentido en el que aquí usamos esta terminología) es que se refieren a entidades no-observables, en cualquier sentido razonable de "observable"; se refieren a entidades determinadas por medios puramente teóricos. La existencia de tales entidades se presupone en la teoría a fin de comprender o "controlar" los fenómenos observables. La asunción de la existencia de entidades teóricas no es una característica exclusiva de las teorías de la física. Otras disciplinas han hecho, a partir de cierto grado de desarrollo, el mismo género de supuestos: los genes en biología, los estados mentales en psicología, la gramática profunda de una lengua en lingüística, el mercado en economía — todos ellos y muchos ejemplos más que podrían añadirse, representan casos de entidades teóricas admitidas en diversos campos de la experiencia para explicar mejor lo que "se ve y se toca". En algunos casos, el desarrollo de la disciplina conduce en definitiva a abandonar la hipótesis de la existencia de dichas entidades (el caso del calórico en termodinámica y del flogisto 
en química son paradigmáticos en este sentido); en otros casos, la entidad asumida acaba por ser "reducida" a otra u otras mejor entendidas, es decir, el término que la denotaba puede ser realmente definido en función de otros términos observacionales o teóricos ("valencia" en química es un claro ejemplo de ello; menos claro es si "gen" también corresponde hoy en día a este caso). No obstante, ni lo primero ni lo segundo representan la regla general. No hay razón para suponer que el decurso de la ciencia conduce progresivamente a un abandono de las entidades teóricas en favor de las observacionales; la tendencia va más bien en sentido contrario.

Situémonos en esta constatación: el análisis tanto diacrónico como sincrónico del discurso científico en general muestra que, a partir de cierto grado de desarrollo conceptual y metodológico, la ciencia acepta la existencia de entidades teóricas no directamente observables por los sentidos, ni siquiera con la ayuda de instrumentos tales como telescopios y microscopios. Se admite que lo que sí es detectable por los sentidos son los efectos de la presencia de dichas entidades. Ahora bien, los efectos observables constituyen un criterio epistémico no unívoco, no siempre exacto y con frecuencia incierto, de la presencia de las entidades teóricas en cuestión. Nadie puede ver pasar un electrón, pero si la aguja de cierto aparato se desplaza de determinada manera, o bien si dentro de una cámara de burbujas se condensan unas gotitas de determinada forma, entonces es probable que por allí haya pasado un electrón, aunque siempre podremos equivocarnos. Los conceptos teóricos no son reducibles a los observacionales, y los criterios empíricos para detectar las entidades que ellos denotan no son unívocos ni completamente confiables. He aquí la gran lección de la filosofía de la ciencia del siglo xx; una lección que ha hecho insostenible la metodología operacionalista, y por lo tanto el positivismo y el empirismo radical, que constituyen su premisa epistemológica.

No quiero ni puedo entrar aquí en la compleja discusión acerca del estatuto ontológico y epistemológico general de las entidades teóricas en comparación con las observacionales, discusión que ha marcado y sigue marcando la filosofía de la ciencia de los últimos decenios. Éste no es el lugar para defender una posición determinada respecto a esta gran cuestión - por ejemplo, defender que el referente de un término teórico es "más real" o "igual de real" o "menos real" que el de un término observacional; no se trata de decidir mediante una argumentación general si, por ejemplo, la realidad está constituida más bien por electrones y campos electromagnéticos que por mesas y árboles, o por ambos tipos de entidades a la vez, o en fin más bien por mesas y árboles solamente. El argumento que defiendo aquí en favor del estatuto ontológico de las naciones y en contra del negacionismo debería ser independiente de la posición que uno adopte frente a la cuestión 
ontoepistemológica general de las entidades teóricas. Dicho de una manera abrupta: en la medida en que los electrones sean reales, también lo son las naciones. Y ambos conceptos son, en cualquier caso, muy útiles para explicar los fenómenos.

Ya hemos constatado que el operacionalismo tuvo muy escasa influencia en las ciencias naturales. Incluso la biología se lo ahorró en gran medida al admitir, después de algunas vacilaciones "operacionalistas" iniciales, los genes, aunque no se vieran ni con el microscopio. En cambio, en el desarrollo de las ciencias sociales, el positivismo y su "brazo militar", el operacionalismo, han causado estragos. El caso más evidente ha sido el del conductismo en psicología; también gran parte de la lingüística pre-chomskyana padeció el mismo virus. Afortunadamente, desde hace un par de décadas, un ámbito considerable de las ciencias sociales ha alcanzado un grado suficiente de desarrollo teórico como para admitir sin rubor la existencia de entidades teóricas, tales como estados mentales o estructuras gramaticales profundas, y cada vez se toman menos en serio los últimos restos de empirismo barato que se manifiestan todavía de vez en cuando. El negacionista en la problemática que aquí nos ocupa quizás es uno de los últimos representantes de dichos restos. . un dinosaurio politológico.

\section{ETNIA Y NACIÓN}

El concepto de nación debería ser admitido como un concepto teórico fundamental de la etnología, la sociología y sobre todo la politología. De hecho, los etnólogos ya hace tiempo utilizan el concepto básico de etnia y sin duda hay que suponer una estrecha relación entre ambos conceptos. Incluso podríamos comprometernos a fondo con la etnología, tomarla como disciplina por así decir "infraestructural" de la politología, identificando el concepto de nación con el de etnia, o mejor aún, subsumiendo el primero como caso particular bajo el segundo. Algunos etnólogos han hecho ya esta propuesta. Por ejemplo, una de las definiciones más aceptables o, mejor dicho, menos frustrantes, que he hallado de los conceptos de etnia y nación, es la que debemos a David Levinson, en su compendio sobre etnología: "El término 'nación' [...] se refiere a un grupo étnico [...] que se ha organizado y movilizado para la acción política [...] Un grupo étnico es un grupo, cuyos miembros poseen un sentimiento compartido de identidad y solidaridad sobre la base de una lengua, religión, cultura, historia o raza compartidas."7

A pesar de su carácter impreciso, la propuesta de Levinson tiene al menos el mérito de señalar la dirección correcta, a saber, subsumir el concepto de

7 Cfr. D. Levinson, Ethnic Relations, ABC-CLIO, Santa Barbara, 1994, p. 83. 
nación bajo el de etnia, y hacerlo de tal manera que la diferencia específica del primero respecto al segundo sea la dimensión política. Por esta razón, el concepto de nación en rigor es más propio de la politología que de la etnología. Podríamos establecer que una nación es una etnia que ha tomado conciencia política de sí misma. La cuestión nacional puede caracterizarse entonces como una cuestión étnica planteada en términos políticos. $Y$ las relaciones inter-nacionales, en sentido propio, deberían entenderse como relaciones entre etnias, cada una de las cuales dispone de su propio programa político de preservación o desarrollo de sí misma. De estas relaciones, entendidas del modo aquí propuesto, es en lo que debería ocuparse una verdadera "Organización de las Naciones Unidas", organización que desafortunadamente está muy lejos aún de haberse constituido.

(Segundo excurso: La elucidación que se propone aquí, siguiendo a Levinson, de los términos "etnia" y "nación" no es, por supuesto, la única posible, ni siquiera la única plausible. En la obra ya mencionada, Luis Villoro propone otra que no carece de cierta plausibilidad y rigor. Atendiendo al uso que del término "pueblo" se hace en el (mal llamado) Derecho Internacional y en las (mal llamadas) organizaciones internacionales (por ejemplo, cuando se habla del "derecho de autodeterminación de los pueblos"), Villoro parece querer fijar el uso de la noción de pueblo para referirse a la unidad colectiva más comprensiva en este contexto; tanto las naciones como las etnias establecidas en un determinado territorio serían subcategorías de dicha unidad: las naciones serían pueblos con autoconciencia política, mientras que el término "etnia" (territorialmente determinada) se reservaría para los pueblos que aún (o ya) carecen de dicha autoconciencia. ${ }^{8}$ No tengo objeciones de principio a la propuesta terminológica de Villoro, y por supuesto que, como buenos filósofos, deberíamos recordar siempre que nomina sunt flatus vocis: en un contexto teórico podemos fijar el significado de los términos, en principio, como nos venga en gana. No obstante, la distinción que hace Villoro entre los términos "pueblo", "nación" y "etnia" no me parece la más adecuada como punto de partida de un análisis teóricoconceptual correcto (aparte de que el propio Villoro parece vacilar en el uso que él mismo propone). El inconveniente básico que veo en su estipulación estriba en que "pueblo" es un término que se ha estirado ya tanto para cubrir un gran número de conceptos realmente distintos (desde "pueblo" como aglomeración de viviendas hasta "pueblo" como clase social opuesta a las élites dominantes, pasando por "pueblo" como soporte virtual de un Estado en la frase "pueblo soberano") que una nueva acepción de dicho término no puede sino añadir más confusión a la ya existente. Me parece mejor la opción de borrar totalmente el término "pueblo" de un contexto teórico serio y sustituirlo sistemáticamente por etnia o nación, habiendo caracterizado previamente estas dos nociones con la mayor precisión posible. Y, digan lo que digan los juristas "internacionalistas",

${ }^{8}$ Cfr. Villoro, op. cit., p. 21. 
no hay mayor problema en sustituir la frase "principio de autodeterminación de los pueblos" por "principio de autodeterminación de las etnias". Fin del excurso.)

La "definición" propuesta por Levinson nos ayuda pues a adelantar camino en el tema. No obstante, deja aún mucho que desear en cuanto al grado de precisión y articulación necesario para tratar la ardua cuestión del nacionalismo. Su principal desventaja es que determina la identidad étnica, y por tanto, por inclusión, la identidad nacional, mediante una amalgama disyuntiva de componentes heteróclitos: "sentimiento de identidad sobre la base de una lengua, religión, cultura, historia o raza compartidas". Dejemos de lado que hay cierta incoherencia en utilizar el concepto de cultura aquí como alternativa al de lengua, religión e historia (como si estos factores no fueran precisamente parte esencial de una cultura) y dejemos de lado también el hecho de que la noción biológica de raza parece en general bastante problemática para la determinación de la identidad étnica. La principal dificultad con la definición de Levinson es que de ella resultaría que una etnia a veces viene determinada por una lengua, a veces por una religión, a veces por una raza, etc. Y entonces no hay más remedio que preguntarse para qué necesitamos el concepto de etnia en general, dado que se trataría sólo de la disyunción de otros conceptos previos, que de todos modos entendemos mejor. ¿Hay algo sustancial en común a los conceptos de lengua, religión, raza, etc.? Parecería que no. En consecuencia, podríamos dudar de la utilidad metodológica del concepto de etnia en general, y del de nación en particular.

Esta dificultad aparece señalada en un artículo enciclopédico de Lincoln Allison sobre la idea de etnicidad. Este autor comienza por constatar con prudencia: "La pregunta de qué sea un grupo étnico, a diferencia de cualquier otra clase de grupo, es una pregunta que no admite una respuesta sencilla." Y después de mostrar con base en una serie de contraejemplos la inadecuación fundamental de la interpretación tradicional de la etnicidad en términos de características raciales, llega a una conclusión resignada: "La etnicidad sigue siendo uno de los aspectos más esquivos y misteriosos de las estructuras sociales, pero también es uno de los más básicos e importantes." 9

La impresión de "misterio" que nos comunica este etnólogo es perspicaz y a la vez sintomática. Sin embargo, ella no tiene por qué conducirnos a abandonar la búsqueda de una mayor precisión en el tratamiento del tema. Las dificultades que rodean una comprensión cabal del concepto de etnia, y por tanto de nación, sólo significan que este concepto, a pesar de su importancia para las ciencias sociales y políticas (o, mejor dicho, debido a

9 Cfr. L. Allison, "Ethnicity", Oxford Concise Dictionary of Politics, op. cit., p. 163. 
ellas), no se puede definir con base en términos más fundamentales y más fácilmente inteligibles. Ésta es justamente la propiedad lógico-metodológica que debemos esperar de cualquier concepto básico en cualquier disciplina: he aquí otra lección que hemos aprendido bien en la filosofía de la ciencia contemporánea. El término "etnia", y su subordinado "nación", denotan entidades político-culturales autónomas, no reducibles, ni ontológica ni epistemológicamente, a otras entidades más básicas como puedan ser la raza, la lengua, la religión, etc. Por otro lado, existe sin duda una conexión significativa entre las primeras y las segundas: raza, lengua, religión, etc. pueden representar manifestaciones fenoménicas de una etnia o nación.

¿Qué hacer entonces con un concepto empírico que, intuitivamente, consideramos útil, o hasta necesario, para cubrir determinado ámbito de nuestra experiencia, pero que se resiste a una definición unívoca satisfactoria? La respuesta metodológica a esta pregunta suele ser siempre la misma en cualquier disciplina, natural o social: construyamos una teoría en la cual el concepto en cuestión desempeñe un papel central (como concepto "primitivo"), prescindamos de cualquier intento de definición u "operacionalización" directa del concepto, y tratemos de aplicar la teoría así construida a los fenómenos que nos interesan para explicarlos mejor.

Dado que, según toda evidencia, ni los etnólogos ni los politólogos hasta ahora se han decidido a construir una teoría tal, me permitiré en este punto cometer otro "pecado de transgresión disciplinaria" y esbozar muy someramente una "miniteoría" de etnias y naciones, fijada por ciertos "axiomas" o principios fundamentales, que han de regir las conexiones de estos conceptos con otros y con el campo de la experiencia fenoménica que tratamos de analizar. Es innecesario advertir que aquí sólo puede tratarse de un esbozo muy provisional, que meramente pretende estimular a los especialistas en dichas disciplinas para que desarrollen una teoría más articulada.

Veamos de manera informal cuáles son los supuestos ontológicos y metodológicos de los que debemos partir para construir nuestra miniteoría, a la que podemos denominar "MEN" ("miniteoría de etnias y naciones"). $\mathrm{He}$ aquí los "axiomas" de $M E N$, acompañados en cada caso de un comentario ilustrativo, un scholium al viejo modo escolástico.

1) Las etnias son entidades aprehendidas a cierto nivel de abstracción de la experiencia. Scholium: a pesar de este nivel de abstracción necesario para su aprehensión no son por ello menos reales que otras entidades reales, fijadas también a cierto nivel de abstracción, que encontramos en las teorías de la física, biología o lingüística (por ejemplo, las entidades a las que se refieren los términos "campo electromagnético", "genoma" o "gramática"). 
2) Las etnias rigen una parte sustancial de la evolución política, social y cultural de la humanidad. Scholium: las etnias constituyen un elemento, no único, pero sí muy importante, de lo que podemos denominar, siguiendo una analogía con la lingüística, la "estructura profunda" de dicha evolución. Precisamente por este carácter "profundo" son de difícil acceso a la investigación empírica directa o "investigación de campo". Su vínculo con los fenómenos culturales y políticos más inmediatamente accesibles puede compararse a la relación que existe entre la estructura profunda y la superficial de una lengua, o entre el genotipo y el fenotipo de un organismo biológico.

3) No podemos investigar cada una de las etnias existentes en un momento dado de manera empírica directa, pero podemos determinar sus características esenciales mediante un razonamiento abductivo a partir de los datos de los que disponemos respecto a sus manifestaciones fenoménicas específicas. Scholium: en este aspecto, las etnias pueden ser investigadas de manera metodológica análoga a tantas otras entidades teóricas de las ciencias avanzadas, de las que hemos dado varios ejemplos más arriba.

4) Las manifestaciones fenoménicas de las etnias son de carácter cultural en la inmensa mayoría de los casos. Scholium: sin embargo, no está excluido que en algunos casos también tengan relevancia los rasgos anatómicos o fisiológicos de los individuos humanos que les pertenecen. Al menos en este estadio de nuestros conocimientos empíricos sobre la materia, MEN no excluye, pero tampoco afirma, la posibilidad de que diferencias genéticas masivas, que puedan constatarse entre grupos humanos diversos, sean decisivas (al menos en algunos casos) para determinar la identidad de una etnia. Es decir, MEN es compatible tanto con un "culturalismo" puro, que excluya cualquier determinación genética de las etnias, como con un "biologismo" moderado, que postule cierto grado de determinación biológica de las etnias, al menos en algunas de ellas. Lo único que excluye MEN es un biologismo absoluto en esta materia. (Éste parece, en efecto, totalmente inverosímil desde un punto de vista empírico; basta tomar como contraejemplo cualquier etnia actual de dimensiones relativamente considerables, como son la inmensa mayoría de las naciones.)

5) La determinación fenoménica de las etnias (casi) nunca es unívoca. Scholium: ninguno de los factores fenoménicos que manifiestan los miembros de una etnia puede considerarse por si solo como una condición necesaria y suficiente de pertenencia a la etnia en cuestión, ni siquiera la lengua, aunque ésta sea en general muy importante para la 
identidad étnica. En consecuencia, no existe un criterio observacional único de determinación de las etnias, como tampoco existe, por cierto, para las entidades teóricas de otras disciplinas. (La presencia de un campo electromagnético, por ejemplo, es inferida a veces por sus efectos luminosos, otras por sus efectos magnéticos, otras por sus efectos eléctricos, o en fin por alguna combinación de todos estos factores; de manera análoga, una etnia o nación a veces se manifestará por su lengua, a veces por su religión, a veces por ciertas tradiciones estéticas, a veces por esa cosa difusa pero no menos real que llamamos una "mentalidad" o "forma de vida", a veces quizás también por rasgos anatómicos o fisiológicos, muchas veces, en fin, por una combinación de todo ello.)

(Tercer excurso: vale la pena en este punto interrumpir brevemente la exposición de los supuestos fundamentales de nuestra teoría y permitirnos una acotación sobre el factor lengua, porque éste es el más característico de la relación entre la estructura superficial y la profunda de la etnicidad. La lengua materna es, sin lugar a dudas, de todos los rasgos fenotípicos de una etnia, el más decisivo en general para su determinación "operacional". Una lengua no es sólo un instrumento de información y comunicación entre seres humanos (como, al parecer, sigue pensando $90 \%$ de los filósofos del lenguaje contemporáneos, $90 \%$ de los cuales sólo conoce una lengua, el inglés). La concepción puramente instrumental del lenguaje valdrá, quizás, para las lenguas adquiridas en nuestra vida adulta; pero la lengua materna, la que aprendemos inconscientemente en nuestros primeros años, es ante todo un modo de expresión de emociones y de una visión del mundo. Esto lo percibió ya claramente el primer gran teórico del nacionalismo, Johann Gottfried Herder, en sus Ideas para una filosofía de la historia de la humanidad, en 1791: Herder señaló que, al ser un factor constitutivo de la identidad personal de cada uno, la lengua materna determina que, a priori, los hablantes de una misma lengua compartan, sin querer, más cosas entre sí que con los hablantes de otras lenguas. No obstante, el propio Herder advirtió que la lengua no lo es todo en la identidad de una nación; hay otros factores quizás aún más profundos y difíciles de acotar. Y empíricamente sabemos que una etnia o nación puede, en el curso de su evolución, perder su lengua originaria total o parcialmente, y, no obstante, preservar su identidad étnica (judíos, irlandeses y gitanos son buenos ejemplos de ello); o bien, en el sentido contrario, dos naciones pueden compartir la misma lengua y, no obstante, ser claramente distintas. (Si alguien duda de ello, puede tomar al azar un grupo de mexicanos y otro de argentinos, y compararlos prescindiendo de las diferencias de acento). La lengua es pues extremadamente importante como factor de etnicidad o nacionalidad, pero sería un grave error considerarlo exclusivo. Por otro lado, la importancia de la lengua como componente esencial de la identidad étnica aparece evidente sobre todo cuando una etnia ha pasado al estadio de nación: incluso en los casos en los que la lengua originaria se ha perdido o está 
a punto de perderse, la nación en cuestión hace esfuerzos sobrehumanos por "revivirla". (Nuevamente el caso judío y el irlandés son paradigmáticos.) Fin del excurso.)

6) Las etnias son entidades genidénticas: cambian preservando su identidad. Scholium: en este punto, las etnias se diferencian sustancialmente de las entidades teóricas de la física y se parecen más a las de la biología, como los organismos o las especies. Las etnias nacen, se desarrollan y mueren (no siempre de "muerte natural", con más frecuencia son asesinadas por otras etnias).

7) Las etnias son entidades de límites sincrónicos y diacrónicos difusos. Scholium: una diferencia esencial entre las etnias y los organismos biológicos es que la ubicación temporal del nacimiento y la muerte de etnias y naciones, así como su ubicación exacta en el espacio geográfico, son mucho más difíciles de determinar que en el caso de los organismos biológicos. Por regla general, los límites espaciotemporales de las etnias son borrosos. Ello no ha de sorprendernos. Se trata de una característica común a casi todas las entidades socioculturales, que no implica nada sobre su estatuto ontológico. No sólo en el campo de la cultura, pero especialmente en él, constatamos la existencia de un sinnúmero de entidades que sin duda son reales pero que deben ser concebidas como "conjuntos borrosos o difusos" (fuzzy-sets). Por ejemplo, es imposible determinar cuándo y dónde exactamente empezó a existir la lengua alemana, ni cómo trazar exactamente la línea divisoria de esa lengua respecto a otras lenguas parecidas; pero ello no implica ni que la lengua alemana sea una ficción inventada por mentes calenturientas ni que sea una entidad idéntica a la lengua rusa, pongamos por caso. (Recomendación general: lo primero que deberíamos hacer en las disciplinas socioculturales es aprender a trabajar con precisión con conceptos imprecisos, sin que el carácter "borroso" de estos últimos nos induzca a pensar que carecen de un referente real.)

8) Las etnias suelen mostrar lo que podemos llamar "diversos niveles de agregación"; es decir, pueden constatarse "subetnias" y "superetnias" respecto a una etnia dada. Scholium: por ejemplo, los bávaros constituyen una subetnia dentro de la etnia alemana: existe sin duda una identidad bávara, incluso muy autoconsciente, que se traduce en un dialecto muy claramente recognoscible de la lengua alemana, tradiciones culinarias muy marcadas, cierta forma de humor y de rela- 
ciones interpersonales, y otros elementos parecidos, e incluso quizás una correlación estadística significativa con ciertos rasgos anatómicos; no obstante, los bávaros pertenecen también a la etnia alemana en general, como queda patente por otra serie de factores objetivamente detectables, así como por la propia percepción subjetiva, tanto de la inmensa mayoría de bávaros como de alemanes no-bávaros. Por otro lado, en el otro extremo del espectro, existe indudablemente una superetnia anglosajona (probablemente la superetnia más poderosa que haya existido jamás en la historia de la humanidad): en efecto, aunque, desde el punto de vista de la teoría $M E N$, ingleses, anglocanadienses, gringos, australianos, neozelandeses y anglosudafricanos constituyen etnias (y por supuesto naciones) distintas, todas ellas forman parte de la superetnia anglosajona, que, en las cuestiones realmente esenciales, revela una extraodinaria homogeneidad y sentido de solidaridad. Por ello, podríamos hablar aquí no sólo de superetnia sino incluso de supernación anglosajona. (Si alguien duda de ello, baste recordar el comportamiento global de las etnias anglosajonas a lo largo del siglo xx en los momentos críticos, como por ejemplo dos guerras mundiales "calientes" y una guerra mundial "fría".)

9) Las naciones constituyen un tipo particular de etnias. Scholium: toda nación es una etnia, pero no toda etnia es una nación. Las naciones son etnias políticamente conscientes de sí mismas, o dicho más concretamente, son etnias que disponen de un programa político (en sentido amplio, o sea, no sólo referido a partidos políticos) de preservación y desarrollo de su propia identidad. De ello se desprende que todas las características que hemos postulado para las etnias en general se aplican también a las naciones, pero a ellas se les añade el componente político.

En resumen, lo que postula la miniteoría aquí propuesta es que etnias y naciones constituyen realidades profundas en la estructura sociocultural de la humanidad. Es cierto que muchas veces será difícil detectarlas y diferenciarlas unas de otras "a primera vista"; pero, en general, lo podremos lograr a través de sus manifestaciones fenoménicas, tales como lengua, religión, mentalidad, etc. (No dispongo de una lista bien definida de factores para rellenar este "etc."; ello debería ser la tarea del investigador empírico especializado, no la de un pobre filósofo de la ciencia.)

Veamos ahora qué consecuencias deontológicas pueden derivarse de nuestra miniteoría (que en sí misma es no-normativa), en particular con respecto a la problemática del nacionalismo. 


\section{Por QuÉ HAY QUE SER NACIONALISTA}

De la teoría expuesta en las páginas anteriores se desprenden ciertas consecuencias ético-políticas si asumimos, además de la teoría, un principio deontológico general, que podemos calificar de principio ético-ontológico y al que podríamos dar el título, algo rimbombante, de principio del "Valor Intrínseco de la Pluralidad del Ser" (o principio "VIPS", para abreviar), a saber: es algo bueno, que hay que preservar, o hasta fomentar en la medida de lo posible, el que haya muchas cosas de muy diversos tipos en el universo. De ello se desprende como corolario que si una cosa existe y no me causa ningún perjuicio, o a lo sumo sólo pequeñas molestias, no tengo por qué empecinarme en destruir su existencia; la destrucción de una entidad sólo está justificada para evitar un daño considerable o para promover un bien muy superior. Si en mi paseo vespertino me topo con un miserable arbusto, no estoy justificado en cortarlo por capricho o sólo porque me hace dar un pequeño rodeo; como seres vivos individuales estamos justificados en eliminar a otros seres vivos sólo cuando nuestra propia existencia depende de ello; estamos justificados en eliminar poblaciones enteras de animales o vegetales sólo en casos extremos de grave peligro para la humanidad. Como regla general, hay que dejar a cada existente que siga su vía. No voy a argumentar largamente en favor de este principio, por un lado, porque me parece éticamente evidente, por otro, porque imagino que la mayoría de las personas "de buena voluntad", como sin duda son los lectores de este ensayo, estarán de acuerdo con él, al menos en términos generales. Pero por si todavía hay algún lector renuente a aceptar el principio VIPS, aduciré un único argumento de carácter en realidad estético: es más bello o atractivo un mundo en el que haya muchas cosas de muy diverso tipo que un aburrido mundo en el que haya sólo pocas cosas de pocos tipos.

Las etnias, hemos visto, son cosas reales, que tienen una existencia propia. Estaríamos justificados en eliminar a las etnias del mundo de los existentes si pudiera demostrarse que su existencia es, por sí misma y en términos generales, causa de graves perjuicios para la humanidad. ¿Hay alguna prueba en este sentido? No la conozco. Por supuesto, podría ocurrir que existiera una etnia concreta que fuera muy perjudicial para todas las demás, por ejemplo porque ella intentara exterminar al resto. Pero ésta es una cuestión completamente distinta. No se trata aquí de averiguar si hay alguna etnia buena o mala, sino de la cuestión de si la existencia misma de etnias en general es algo malo. No veo ninguna razón para aceptar esta hipótesis. Al contrario, de acuerdo con el principio VIPS, parece claro que es bueno (o al menos más divertido) que haya no sólo muchos tipos de astros, de minerales, de vegetales, de animales y de seres humanos individuales, sino también que haya diversos tipos de grupos humanos, siempre y cuando, 
claro está, todos estos tipos de cosas no nos hagan la vida imposible a los demás.

El contranacionalista (quien, tal como lo hemos definido, no es alguien que niega la realidad de las naciones, sino su carácter positivo o siquiera inocuo) puede aducir en este punto que él no tiene ningún problema con la existencia de etnias diversas, sino con la de naciones, o al menos con el nacionalismo como programa político. Analicemos entonces la cuestión de cómo se puede pasar de la existencia de etnias al nacionalismo, y por qué los temores del contranacionalista son infundados.

Las etnias no sólo existen, sino que en muchos casos (aunque no en todos) se esfuerzan por preservar su existencia. De acuerdo con VIPS, parece que están en su perfecto derecho. Cuando este esfuerzo por preservar su existencia (con frecuencia en condiciones más o menos desfavorables) se traduce en un programa de acción política, conscientemente apoyado por una parte significativa de la población, tenemos que la etnia en cuestión se ha transformado en una nación, y al programa concomitante lo podemos calificar de "nacionalista". Ese programa no tiene por qué ser en todos los casos idéntico a un proyecto de Estado-nación soberano: para preservarse y desarrollarse satisfactoriamente, la etnia en cuestión puede constatar que le basta con cierta dosis de autonomía dentro de un Estado multinacional, es decir, en convivencia pacífica con otras etnias. Éste es sin duda un arreglo ideal. No obstante, hay que reconocer que este tipo de arreglo políticoadministrativo funciona las más de las veces bastante mal, por no decir que no funciona en absoluto. Para limitarnos al ejemplo de Europa, la gran mayoría de los Estados soberanos existentes en esta región del globo deben ser considerados como Estados definitivamente multiétnicos. En muchos de ellos, las diversas etnias que los componen han desarrollado suficiente autoconciencia política como para que un observador imparcial les confiera el estatuto de naciones. Pero, excepto en los ejemplos modélicos de Finlandia y Suiza, la conviviencia de las diversas naciones que componen dichos Estados se halla lejos de la armonía. El conflicto intraestatal entre naciones puede adoptar formas más o menos virulentas, desde una situación de antipatía mutua generalizada o de tensión permanente, pasando por brotes esporádicos de violencia, hasta llegar a un conflicto armado de larga duración; en cualquier caso, una vida difícil. . .

¿Por qué es tan difícil que funcione bien un Estado multinacional, aunque, en teoría sería la solución ideal? Creo que la razón es bastante fácil de entender. Ella no es de orden conceptual, sino estrictamente histórico-empírica; es decir, no hay en sí nada erróneo en la idea de un Estado multinacional, pero siendo la historia de las relaciones internacionales la que es, esa idea es muy difícil de realizar. La razón es que, en la inmensa mayoría de los 
casos, los Estados multinacionales realmente existentes son, por causas históricas contingentes, no Estados constituidos por el consenso de las diversas etnias que los componen, sino por la voluntad, muchas veces extremadamente violenta, de una sola etnia predominante. En una palabra, se trata de Estados-nación hegemónicos (o sea, que promueven la hegemonía de una sola etnia sobre las demás). Hay en ellos una nación que les dicta a la otra u otras cómo tienen que ser las cosas en el orden político, jurídico, lingüístico, religioso, económico, de relaciones internacionales, etc. Generalmente, la nación predominante dentro de un Estado multinacional lo es por su simple peso demográfico, porque es la que integra la mayor parte de la población; pero hay excepciones a esta regla, cuando la que se impone es la nación más belicosa o agresiva, como muestran los casos de la Unión Sudafricana, la antigua Yugoslavia y Burundi, en los que una etnia que abarca menos de $50 \%$ de la población impuso en su momento su regla a la otra u otras etnias, al menos hasta que éstas se cansaron.

Es obvio que tales situaciones de predominio de una nación sobre otras, tan frecuentes en los Estados multinacionales, son situaciones de injusticia. Si admitimos que las etnias existen y que cada una tiene el derecho a preservarse y desarrollarse al menos hasta que se muera de "muerte natural" - y no por ser asesinada-, entonces debería estar claro que es una obligación fundamental de cualquier Estado multinacional crear y mantener las condiciones político-jurídicas adecuadas para que cada una de las naciones que lo componen, independientemente de su peso demográfico, de animadversiones históricamente condicionadas, o de cualquier otra consideración, se sienta, por así decir, "a gusto en casa", en esa casa administrativa que, en definitiva, es cualquier Estado. Ello puede complicar las leyes, la jurisprudencia, las instituciones educativas, el manejo de la política día a día, de la economía, etc.; pero no hay más remedio que hacerlo así si se quiere implementar la justicia, no sólo en la relación entre los ciudadanos individualmente considerados, sino también en la relación entre las naciones con las que esos ciudadanos se sienten identificados. La democracia siempre es más complicada que el autoritarismo, pero eso no es ningún buen argumento en contra de la primera o a favor del segundo. Y si el Estado multinacional en cuestión, por las razones que sean, se ve en la incapacidad de crear las estructuras político-jurídicas que permitan tratar en pie de igualdad a todas las naciones que lo componen, entonces es un imperativo ético-político que deje que se vaya de casa la nación que así quiera hacerlo. Si un padre de familia, por razones económicas, psicológicas o de cualquier índole, se ve en la incapacidad de tratar en pie de igualdad a todos sus hijos, entonces debe aceptar que, quien así lo quiera, abandone el hogar paterno y vaya a formar su propio hogar - por muy "irracional" que ello le parezca 
y aunque ello pueda traer consigo ciertas desventajas de índole práctico, económico, psicológico, etc. Esta constatación me parece tan evidente que adquiere casi el carácter de una perogrullada moral; pero al parecer es una perogrullada que les cuesta mucho aceptar a algunos padres de familia, y aún más a los Estados multinacionales, con las consecuencias trágicas que todos conocemos. Esta perogrullada, entendida como programa político, es lo que se llama "nacionalismo". Y el contranacionalista es alguien que no entiende, o no quiere entender, esa perogrullada.

Creo que la ceguera del contranacionalista ante la perogrullada éticopolítica que significa el nacionalismo tiene su raíz profunda en una confusión, de naturaleza conceptual y empírica a la vez, de funestas consecuencias. El programa nacionalista por el que aquí se aboga no conlleva en absoluto el programa de una actitud agresiva de una nación hacia otra. Supongo que a estas alturas del texto es innecesario subrayar este punto. Sin embargo, también es evidente que las discusiones en torno a esta temática se han solido llevar a tal nivel de indigencia conceptual que el término "nacionalismo", como programa de afirmación de una nación, se ha usado indistintamente tanto para la afirmación defensiva como para la agresiva de una nación frente a otra u otras. Con lo cual se mete en el mismo saco, pongamos por caso, el programa supuestamente "nacionalista" de Hitler y el programa genuinamente nacionalista de Gandhi. Y como ninguna persona de buena voluntad puede estar a favor del programa de Hitler, se desprende con un rigor aparentemente aplastante que la misma persona de buena voluntad tampoco puede estar a favor del programa de Gandhi. Lo cual, manifiestamente, es una reductio ad absurdum politológica. Ella proviene simplemente de la confusión deontológica elemental entre la afirmación del derecho de existencia de una nación y la negación del derecho de existencia de otras naciones. Es a la primera afirmación a lo que, con pertinencia terminológica y conceptual, conviene caracterizar como "nacionalismo". La denominación propia para la negación opuesta no es "nacionalismo" sino "imperialismo", "racismo" o, de manera más exacta aún, "hegemonismo".

El nacionalismo genuino sólo reclama el derecho a la existencia de una nación en pie de igualdad con otras naciones; el hegemonismo, con frecuencia mal llamado "nacionalismo", reclama el derecho de una nación a subyugar o incluso erradicar a otras naciones, en nombre de una supuesta superioridad racial, cultural, económica o del tipo que sea. Es difícil imaginar dos posiciones políticas más antagónicas. Y está claro que no se trata aquí de una distinción meramente académica. El ignorarla puede llevar fácilmente a graves errores de interpretación de los sucesos políticos. Para dar un solo ejemplo: fue una experiencia muy deprimente constatar como, durante las recientes guerras en los Balcanes, desde la agresión de Servia 
a Eslovenia en 1991, hasta el intento de genocidio contra los albaneses kosovares en 1999, la llamada "opinión pública" mundial, y en particular muchos intelectuales liberales, ubicaron invariablemente en el mismo rubro de "nacionalismo" tanto el hegemonismo servio como el patriotismo de todos los demás pueblos balcánicos que querían zafarse del yugo servio. Tales errores de apreciación, repulsivos cuando no trágicos, podrían evitarse fácilmente si se tuvieran los conceptos correspondientes mínimamente claros.

Por supuesto que, en ciertas circunstancias complejas o desfavorables, ha ocurrido alguna vez que el nacionalismo ha derivado peligrosamente hacia el hegemonismo, de modo análogo a como el ideal de justicia social ha derivado muchas veces hacia el totalitarismo más atroz. Lo primero ocurrió, por ejemplo, en la Alemania de entreguerras, cuando un programa nacionalista en principio inobjetable, que señalaba las consecuencias intolerables del Tratado de Versalles, fue recuperado desvergonzadamente por el super-hegemonismo nacionalsocialista; o, para poner otro ejemplo más reciente, hubo una peligrosa tendencia al hegemonismo en algunos sectores del nacionalismo croata durante la Guerra de los Balcanes (aunque afortunadamente parece que ha sido atajada a tiempo). Pero del mismo modo como todos los Stalins, Maos y Pol Pots del mundo no son un buen argumento en contra de un programa genuinamente socialista, tampoco todos los Hitlers, Mussolinis y Milosevics representan una refutación moral del ideal nacionalista.

Debería ser justamente el compromiso teórico y práctico de políticos e intelectuales con ideas claras velar porque el nacionalismo en su propio país, que siempre es correcto defender, no derive hacia tendencias hegemónicas, que siempre es correcto contrarrestar. En una palabra, el único nacionalismo políticamente correcto es un nacionalismo internacionalista. Esto puede sonar a paradoja, o a juego de palabras de una mala dialéctica, pero no lo es. Después de lo expuesto hasta aquí debería estar perfectamente claro lo que significa: toda nación tiene el derecho, y hasta la obligación, de hacer lo posible por preservar su identidad; y al mismo tiempo tiene la obligación de respetar las condiciones para que las otras naciones preserven la suya. En el nivel de colectividades humanas ocurre aquí exactamente lo mismo que en el nivel de los individuos mismos.

Es indudable que (al igual que en el caso de los individuos) en ocasiones pueden surgir conflictos de intereses legítimos; el caso típico es aquel en que dos naciones se sienten parcial o totalmente vinculadas al mismo territorio geográfico. Pero, como en tantos otros casos de conflictos políticos, sociales, económicos y culturales, también estos casos pueden resolverse a través de negociaciones y compromisos. La regla de oro consiste en tomar como punto 
de partida que, sean cuáles sean los legítimos intereses de una nación, ellos nunca pueden implicar la desaparición o el sometimiento de otra nación. Si los judíos y árabes de Palestina se hubieran atenido a esta norma desde 1948, se habrían ahorrado muchas muertes, destrucciones y sufrimientos.

El verdadero enemigo de una política nacionalista no es otra política nacionalista. El verdadero enemigo del nacionalismo es el hegemonismo. Aunque este último tiene muy buenas cartas (económicas, militares, lingüísticas, culturales) en la actualidad, debido al enorme poder que acumulan los grandes Estados hegemónicos modernos, no creo que ya esté dicha la última palabra en este asunto y que los nacionalistas deban resignarse al triste destino de ver desaparecer a sus naciones, más o menos lenta o rápidamente, más o menos violenta o solapadamente. En esta cuestión, como en tantas otras, la unión puede hacer la fuerza y contrarrestar eficazmente la realización del proyecto perverso de unos cuantos grandes Estados hegemónicos sobre la Tierra, o incluso la pesadilla abismal de un solo Estado hegemónico (anglosajón) mundial. Por ello espero que me esté permitido concluir este modesto manifiesto con una paráfrasis paralela a aquella con la que comenzó, y que representa simplemente el corolario práctico de la teoría aquí expuesta: "Naciones (humilladas y ofendidas) de todo el mundo: uníos (contra los Estados hegemónicos)." 